\title{
OS DESAFIOS, AS LIMITAÇÕES E AS PERSPECTIVAS DO MODELO DO ÍNDICE DE COMPETITIVIDADE TURÍSTICA NO CONTEXTO DA POLÍTICA NACIONAL DE TURISMO BRASILEIRA
}

\author{
CHALLENGES, LIMITATIONS AND PERSPECTIVES OF THE TOURISM COMPETITIVENESS INDEX \\ MODEL WITHIN THE CONTEXT OF THE BRAZILIAN TOURISM NATIONAL POLICY
}

\author{
LOS DESAFIOOS, LAS LIMITACIONES Y LAS PERSPECTIVAS DEL MODELO DEL ÍNDICE DE \\ COMPETITIVIDAD TURÍSTICA EN EL CONTEXTO DE LA POLÍTICA NACIONAL BRASILEÑA DE TURISMO
}

Isabela Rosa Sette

Mestranda em Turismo na EACH/USP

Especialista em Turismo e Desenvolvimento Sustentável pela UFMG isabelasette@usp.br

Edegar Luis Tomazzoni

Docente do Mestrado em Turismo; Mestrado em Mudança Social e Participação Política e do Curso de Lazer e Turismo da EACH/USP Doutor em Ciências da Comunicação com Ênfase em Turismo pela ECA/USP eltomazzoni@usp.br

Data de Submissão: 06/09/2016 Data de Aprovação: 04/04/2017

RESUMO: O objetivo deste artigo é analisar os desafios, as limitações e as perspectivas do modelo do Índice de Competitividade Turística no contexto da política nacional brasileira de turismo. A metodologia de pesquisa envolveu análise documental e bibliográfica e observação participante, além da aplicação e da análise de entrevistas com 14 representantes do Ministério do Turismo, do Sebrae Nacional e da Fundação Getúlio Vargas, instituições responsáveis pela criação do índice. Dentre as limitações destacadas, está o excesso de uniformidade na coleta e na análise de dados; a não consideração da opinião da demanda e a visão unânime de que os resultados do Índice de Competitividade ainda são subutilizados pelos destinos e demais instituições interessadas, tal como o próprio Ministério do Turismo. Como desafios e perspectivas, foi ressaltado que a amostra dos então 65 destinos indutores foi, a princípio, definida como parte de uma estratégia da política nacional de turismo, que foi descontinuada e os destinos não são mais classificados como indutores. Dessa forma, o Índice de Competitividade Turística passou a ser uma ferramenta apenas de monitoramento ou de diagnóstico para os destinos.

PALAVRAS-CHAVE: Turismo; Competitividade; Destinos Turísticos; Ministério do Turismo (Brasil).

\begin{abstract}
The objective of this paper is to analyse the challenges, limitations and perspectives of the model of the Tourism Competitiveness Index within the context of Brazilian tourism national policy. The research methodology included documentary and bibliography analysis and participant observation, as well as interviews with 14 representatives of the Ministry of Tourism, the National Sebrae and the Getulio Vargas Foundation, institutions responsible for creating the Index. Among the highlighted limitations, is the excess of uniformity in data collection and analysis; the omission of the opinion of the demand and the unanimous view that the results of the Competitiveness Index are still underutilized by the destinations and other interested institutions, such as the Ministry of Tourism. As for the challenges and perspectives, it was pointed out that the Index does not consider the opinion of the demand. The sample of the then 65 destinations was, in principle, defined as part of a national tourism policy strategy, which has been discontinued. The destinations are no longer classified as inductors. Therefore, the Tourism Competitiveness Index has become just a tool for monitoring or diagnosing the destinations.
\end{abstract}

KEYWORDS: Tourism; Competitiveness; Tourist Destinations; Tourism Ministry (Brazil).

RESUMEN: El objetivo de este artículo es analizar los desafíos, las limitaciones y las perspectivas del modelo del Índice de Competitividad Turística en el contexto de la política nacional brasileña de turismo. La metodología del estudio incluyó análisis documental y bibliográfico y observación participante, además de la aplicación y del análisis 
de entrevistas con 14 representantes del Ministerio de Turismo, del Sebrae Nacional y de la Fundación Getúlio Vargas, instituciones responsables por la creación del índice. Entre las limitaciones destacadas está el exceso de uniformidad en la recolección y análisis de datos, la no consideración de la opinión de la demanda y la visión unánime de que los resultados del Índice de Competitividad todavía son subutilizados por los destinos y demás instituciones interesadas, tal como el propio Ministerio de Turismo. Como retos y perspectivas, se destacó que la muestra de los hasta entonces 65 destinos inductores fue, en principio, definida como parte de una estrategia de la política nacional de turismo que fue descontinuada y los destinos no son más clasificados como inductores. De esta forma, el Índice de Competitividad Turística pasó a ser únicamente una herramienta de monitoreo o de diagnóstico para los destinos.

PALABRAS CLAVE: Turismo; Competitividad; Destinos Turísticos; Ministerio de Turismo (Brasil).

\section{INTRODUÇÃO}

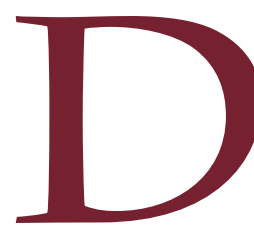

esde a década de 1990, tem aumentado o número de pesquisas para avaliar os aspectos da competitividade de destinos turísticos (Crouch, 2007). Gândara et al. (2012) destacam que a crescente oferta de produtos e serviços turísticos tem "forçado" os planejadores do turismo a investirem na qualidade na prestação dos serviços turísticos como estratégia diferenciadora (p. 384). A razão disso tem ligação a aspectos como pressões competitivas, amadurecimento de mercados e mudança nos hábitos dos consumidores. Isso se deve, em parte, ao crescimento da demanda turística em escala global - de acordo com a Organização Mundial de Turismo (Unwto, 2015), mais de um bilhão de pessoas viajaram pelo mundo em 2014 - e ao surgimento de novas destinações.

Segundo Alves e Ferreira (2008), o conceito de competitividade tem sido frequentemente discutido na literatura no campo da estratégia, em âmbito empresarial na economia internacional. As autoras ressaltam, no entanto, que modelos teóricos relacionados à competitividade de destinos turísticos envolvem questões desafiadoras. Definir e mensurar a competitividade é tarefa difícil, por envolver diferentes conceitos e escopos, além da falta de consenso na literatura sobre o tema (Barbosa, 2008).

Schuch (2001) argumenta que as especificidades - rigidez dos componentes de fornecimento, instabilidade e sensibilidade da procura, concorrência entre destinos e distribuição - constituem o conjunto de especificidades que tornam o produto-turismo diferente dos produtos da era pós-industrial. "No turismo, o consumidor compra um produto com "várias etiquetas" (de todas as 
organizações que intervêm no pacote), o que faz com que a qualidade percebida seja a do conjunto e não a das partes isoladamente" (p. 46).

Para o autor, as empresas dos subsistemas (alojamento, transporte, atrativos e serviços de apoio) devem ter objetivos e estratégias comuns. "É fundamental identificar as perspectivas para os elos da cadeia produtiva do turismo e identificar seus índices de desempenho adequados, de modo que se possa monitorar sua eficiência, seu desempenho e sua evolução histórica" (p. 46).

No Brasil, o Ministério do Turismo (MTur), juntamente com a Fundação Getúlio Vargas (FGV) e o Sebrae Nacional, desenvolveu uma metodologia para mensurar a competitividade de destinos turísticos, o Índice de Competitividade Turística. Criado em 2008, o modelo propõe o diagnóstico de treze dimensões do desenvolvimento do turismo de um destino e envolve a análise de dados secundários, além de uma coleta de dados primários in loco (Barbosa, 2008).

Para aplicação do índice, foram selecionados 65 destinos turísticos, no âmbito do Programa de Regionalização do Turismo - Roteiros do Brasil, para "obtenção de um padrão de qualidade internacional de mercado", conforme disposto no Plano Nacional de Turismo 2007/2010 - Uma Viagem de Inclusão (Brasil, 2007, p. 52). Os chamados destinos indutores foram selecionados a partir da priorização de 87 roteiros, e os 65 destinos seriam aqueles que teriam capacidade de induzir o desenvolvimento regional entre os roteiros citados (Barbosa, 2008).

O índice de competitividade foi aplicado nos 65 destinos indutores, anualmente, de 2008 a 2015, com exceção de 2012. No Plano Nacional de Turismo 2013/2016, a mensuração da competitividade manteve-se como uma das ações do Ministério do Turismo, como parte da macro ação de "estruturar os destinos turísticos" (Brasil, 2013, p. 83).

A despeito da aplicação do índice por sete edições, não se encontram muitos estudos voltados a analisar a metodologia adotada no que se refere às suas limitações, tampouco refletir acerca das perspectivas e dos desafios futuros. Acredita-se que essa reflexão possa oferecer subsídios para a revisão da estratégia ligada ao Índice pelo Ministério do Turismo, assim como para o aprimoramento da metodologia. Os resultados desta pesquisa podem ainda 
contribuir com a elaboração de novos modelos de aferição da competitividade turística, principalmente por ponderar sobre as limitações do modelo em questão a partir da ótica técnica.

Nesse sentido, o problema da pesquisa é: são percebidas limitações na metodologia de mensuração no índice de competitividade turística por profissionais envolvidos diretamente em sua aplicação, do ponto de vista técnico, e quais seriam os principais desafios e perspectivas que permeiam a sua utilização e continuidade? O objetivo deste artigo é analisar os desafios, os aspectos limitantes e as perspectivas do modelo do Índice de Competitividade Turística no contexto da política nacional de turismo brasileira do ponto de vista de seus técnicos e dos técnicos do Sebrae Nacional, que tiveram um contato mais próximo com a metodologia e, principalmente, da equipe da Fundação Getúlio Vargas (FGV), responsável pela sua operacionalização.

Para tanto, realizou-se revisão teórica dos conceitos de competitividade e competitividade de destinos turísticos, além dos principais aspectos ligados ao Programa de Regionalização do Turismo - Roteiros do Brasil, definição dos 65 destinos indutores e, mais especificadamente, um detalhamento da metodologia do índice de competitividade turística adotado pelo MTur. Para subsidiar a análise dos desafios, aspectos limitantes e perspectivas acerca do Índice de Competitividade, além de outros procedimentos, foram realizadas entrevistas com representantes do Ministério do Turismo, do Sebrae Nacional e da Fundação Getúlio Vargas, instituições responsáveis pela criação do Índice.

\section{COMPETITIVIDADE DE DESTINOS TURÍSTICOS}

Está-se vivendo em um mundo cuja competição está cada vez mais implacável e incessante. Segundo Ritchie e Crouch (2003), a noção de competitividade vem sendo constantemente discutida no mundo dos negócios, principalmente a partir dos estudos do Professor Michael Porter (1985 e 1990).

O conceito de competitividade, quando analisado de maneira superficial, pode parecer simples. Quando, no entanto, se tentam estabelecer métodos, percebe-se a dificuldade de sua definição. A competitividade é um conceito 
relativo (é competitivo em comparação "a"?) e muldimensional (quais seriam as principais qualidades a serem analisadas?). Ainda segundo Ritchie e Crouch (2003), outras dificuldades da mensuração da competitividade são a perspectiva de análise e os interesses dos diferentes públicos: políticos se interessam pela competitividade econômica em diferentes escalas (local, regional ou nacional); na escala industrial, empresários e gestores têm interesse na sua área de atuação.

Os autores Ruiz e Gândara (2014) destacam a multidisciplinariedade do conceito de competitividade, apresentando diferentes definições de autores:

Quadro 1 - Conceitos de Competitividade

\begin{tabular}{|c|c|}
\hline Autor (ano) & Conceito de Competitividade \\
\hline Scott e Lodge (1985) & $\begin{array}{c}\text { A habilidade de uma nação em produzir e distribuir bens e serviços na } \\
\text { economia internacional, de modo que também aumente o padrão de } \\
\text { vida da população. }\end{array}$ \\
\hline Haguenauer (1989) & $\begin{array}{c}\text { A competitividade é associada à capacidade de uma indústria de } \\
\text { produzir bens com maior eficácia que os concorrentes no que } \\
\text { se refere a preços, qualidade, tecnologia, estando relacionada às } \\
\text { condições gerais ou específicas em que se realiza a produção da } \\
\text { indústria vis-à-vis à concorrência. }\end{array}$ \\
\hline Crouch e Ritchie (1999) & $\begin{array}{c}\text { Competitividade é a capacidade de agregar valor e, assim, aumentar } \\
\text { a riqueza pela gestão de bens e processos através da integração } \\
\text { dessas relações, dentro de um modelo econômico e social que leva em } \\
\text { consideração o capital natural do destino e a sua preservação para as } \\
\text { gerações futuras. }\end{array}$ \\
\hline
\end{tabular}

Fonte: Ruiz e Gândara (2014)

Segundo Onsel et al (2008), a competitividade fundamenta-se nas economias das nações com níveis de desenvolvimento similares. Para o autor, a capacidade das empresas depende da eficiência das instituições públicas, da excelência educacional, das infraestruturas de saúde e comunicação, e da estabilidade política e econômica do país. A inovação é também destacada como importante componente da competitividade (Cinicioglu et al, 2013). Para o Fórum Econômico Mundial (WEF, 2015), competitividade é "[...] conjunto de instituições, políticas e fatores que determinam o nível de produtividade de uma economia, que, por sua vez, define o nível de prosperidade que o país pode atingir" (tradução nossa) (p. 4).

Segundo Oliveira (2013), entre outras abordagens, são encontradas duas principais convergências nos estudos relacionados ao tema, que se relacionam a: 1) unidades ou níveis de análise e fatores; e 2) mensuração ou critérios 
de avaliação: os estudos podem ser divididos entre aqueles que têm como base aspectos de desempenho e os que estão ligados à eficiência. O autor ressalta que os modelos, que têm como base noções de desempenho, estão associados a um conceito ex-post, ou seja, a competitividade de uma economia é medida a partir de seus efeitos sobre o comércio exterior. Nesse aspecto, a competitividade é avaliada por meio dos resultados de ações efetivamente executadas. Os modelos fundamentados na eficiência são eminentemente exante, isto é, baseados na capacidade de produção e técnica setoriais, ou seja, nas características estruturais da unidade analisada.

Em destinos turísticos, a questão da competitividade torna-se ainda mais desafiadora em razão da natureza complexa do fenômeno turístico. 0 tema vem atraindo constante atenção de autores ligados ao turismo, sendo entendido como um importante componente do sucesso de destinos turísticos (Goroochurn e Sugyarto, 2005).

De acordo com Buhalis (2000), destinos podem ser entendidos como amálgamas de produtos turísticos, de modo a oferecer uma experiência integrada aos turistas. Lohmann e Panosso Netto (2012) reiteram que um destino turístico pode ser um vilarejo, uma cidade, uma região, uma ilha ou até países inteiros. A definição envolve diversos fatores, como a motivação da viagem, a percepção dos turistas e a estratégia de marketing. "Um destino pode ser uma única localidade, um conjunto de múltiplos destinos, como parte de um tour, ou um destino móvel, como no caso dos cruzeiros marítimos", conforme destacado por Lohmann \& Panosso Netto (2012, p. 353).

Com objetivo de desenvolver uma proposta sistêmica de planejamento e gestão de territórios turísticos (aqui entendido como sinônimo de destino turístico), baseada nos princípios de sustentabilidade ecológica, econômica e social, Anjos (2004) apresentou modelo com base "na perspectiva sistêmica e na visão estratégica de Acerenza (1987 e 1992), na abrangência e na preocupação econômica da proposta de Bote Gómez (1990), na visão política e sustentável do planejamento da proposta de Hall (2001), na preocupação sistêmica e sustentável da proposta de Vera Rebollo e Yvars Baidal (2001) e no cuidado com o planejamento e gestão autonomista de Souza (2001; 2003)." (Anjos et al, 2013, p. 404). 
Para Heath (2003), a competitividade de destinos turísticos é a capacidade de os locais oferecerem produtos e serviços melhores que outros destinos. Hassan (2000, apud Heath, 2003) considera como destino competitivo aquele que cria e agrega valores aos seus produtos, enquanto mantém sua posição de mercado em relação aos competidores. Os autores Ritchie e Crouch (2003) reiteram que a dimensão econômica é importante para a competitividade do turismo, porém se deve considerar também aquelas ligadas ao social, cultural, político, tecnológico e ambiental.

Enright e Newton (2004) consideram que um destino é competitivo na medida em que atrai turistas, sendo sua competitividade determinada por fatores específicos do turismo como por outros indiretos, que influenciam os prestadores de serviços turísticos.

Nessa perspectiva, e contextualizando o turismo no desenvolvimento regional, Tomazzoni (2007) desenvolveu o modelo Arranjo Produtivo Local do Turismo, que denominou de APL-TUR. O modelo estrutura-se em elementos, que constituem as dimensões econômica, cultural e organizacional. Todos os elementos são representados por indicadores qualitativos e quantitativos.

Mazaro e Varzin (2008) realizaram comparação entre características principais de modelos de interpretação da competitividade turística. Os modelos analisados por esses autores foram: 1) Coordenadas - Bosh Campubrí (1998), 2) Sistema Interfuncional Integrado (SIIC) - Toledo et al. (1998), 3) Premierranking - Genest y Legg (2003), 4) Competitividade de Destinos - Ritchie e Crouch (1999, 2003). As características observadas são: motivações para seu desenvolvimento, objetivos do modelo, aspectos metodológicos, dimensões de sustentabilidade, categorias de fatores principais, impactos. As dimensões da sustentabilidade são respectivamente: 1) meio ambiental, 2) econômica, 3) econômica com riscos culturais e meio ambientais, 4) meio ambiental, cultural, econômica e governamental.

Crouch (2007a) destaca que as pesquisas sobre competitividade de destinos turísticos se dividem, basicamente, em três categorias: 1) com objetivo de diagnosticar a posição competitiva; 2) com foco em aspectos particulares, tais como posicionamento, sistema de gerenciamento, marketing, preço, qualidade, 
gerenciamento estratégico; e 3) os que se dedicam ao desenvolvimento de modelos e teorias gerais de competitividade de destinos turísticos.

Alguns autores, tais como Ritchie e Crouch (2003), Dwyer e Kim (2003) e Crouch (2007a), propõem modelos de mensuração de competitividade de destinos turísticos. O Fórum Econômico Mundial utiliza modelo conhecido como Travel \& Tourism Competitiveness Index (TTCI), aplicado desde 2007. Neste, competitividade turística é o "conjunto de fatores e políticas que permitam o desenvolvimento sustentável do setor de Viagens e Turismo que contribui para o desenvolvimento e competitividade de um país" (tradução nossa) (WEF, 2015b, p. 7).

Além destes, há ainda os modelos de Enright e Newton (2004); o Monitor de Competitividade Turística de Gooroochurn e Sugiyarto (2005); o modelo explicativo de Mazanec; Wober e Zins (2007); o modelo da abordagem de comparação de desempenho de destinos, aplicado nas regiões francesas de Botti et al. (2009; o modelo baseado na produtividade de Knezecic Cvelbar et al. (2016); entre outros.

Diante do exposto, são significativos os estudos da competitividade turística, bem como a complexidade de proposição de modelos com o objetivo de mensurá-la e avaliá-la. No Brasil, o modelo adotado pelo Ministério do Turismo foi desenvolvido em parceria com a Fundação Getúlio Vargas (FGV) e o Sebrae Nacional, a partir do Programa de Regionalização do Turismo, conforme será abordado em tópico específico.

\section{O PROGRAMA DE REGIONALIZAÇÃO E OS DESTINOS INDUTORES}

De acordo com Araujo e Taschner (2012), a política nacional de turismo no Brasil assumiu maior visibilidade nos anos 1990, com a transformação da Embratur em Instituto Brasileiro de Turismo. Naquele período, foi instituído o Programa Nacional de Municipalização do Turismo (PNMT), para ampliação da autonomia e da participação dos estados e municípios. Foi uma mudança de modelo pela descentralização das políticas. A criação de Conselhos e de Fundos de turismo e os planos de desenvolvimento turístico municipais foram 
suas diretrizes (Araújo e César, 2012). Apesar de importante iniciativa, o PNMT gerou resultados pontuais.

O Ministério do Turismo (MTur), como pasta exclusiva, foi criado em 2003, marco na história do turismo brasileiro. A Embratur passou, então, a ser responsável pelo marketing, comercialização e divulgação do Brasil no exterior (Araújo e Taschner, 2012).

Em 2004, o MTur lançou o Programa de Regionalização do Turismo - Roteiros do Brasil -, que substituiu o PNMT. Esse programa propunha a ampliação da atuação, antes focada no município, para as regiões turísticas, tendo como base a gestão descentralizada, estruturada sob os princípios da flexibilidade, articulação e mobilização regional. Segundo Araújo e César (2012), "um dos propósitos do programa era promover a desconcentração da oferta turística brasileira, localizada predominantemente no litoral, propiciando a interiorização da atividade e a inclusão de novos destinos aos roteiros comercializados [...]", (p. 274).

O Plano Nacional de Turismo 2007/2010 apresenta que, inicialmente, o mapa da regionalização era composto por 219 regiões turísticas, envolvendo 3.203 municípios. Após a primeira edição do Salão Nacional do Turismo (que teve como objetivo apresentar os produtos e roteiros turísticos do país), em 2005, foram realizadas várias reuniões, seminários e oficinas para reorganização da oferta turística nacional. Naquele momento, o Mapa da Regionalização do Turismo foi atualizado, passando a reunir 200 regiões turísticas e 3.819 municípios (Brasil, 2007). Para o $2^{\circ}$ Salão Nacional do Turismo (realizado em 2006), foram selecionados 396 roteiros, envolvendo 149 regiões turísticas. Desse total, foram eleitos, novamente, "87 roteiros para serem trabalhados com o objetivo de alcançar o padrão internacional de qualidade" (Brasil, 2007, p. 26).

De acordo com o MTur (Brasil, 2007), considerando o Plano de Marketing Internacional, Plano Aquarela e outros estudos e pesquisas sobre os investimentos do governo federal, além da análise da potencialidade e infraestrutura dos municípios, foram definidos 65 destinos indutores a partir desses roteiros, que teriam o papel de induzir o desenvolvimento turístico em suas regiões. Para o MTur, tais destinos possuíam infraestrutura básica e turística, além de atrativos qualificados, para distribuir o fluxo em âmbito regional (Barbosa, 2008). 
Ao menos em tese, os esforços seriam concentrados nesses destinos, a fim de elevar a sua competitividade turística. Todas as unidades da federação foram contempladas e foi estabelecido o mínimo de um e o máximo de cinco destinos indutores por estado (Barbosa, 2008).

Sem a pretensão de aprofundar o assunto, é importante ponderar que os critérios para definição dos 65 destinos indutores não foram expostos de maneira clara pelo MTur, tendo sido alvos de questionamentos. Com o intuito de mensurar e monitorar a competitividade desses destinos indutores, o MTur, em parceria com a FGV e o Sebrae Nacional, elaborou a metodologia do Índice de Competitividade Turística, objeto do tópico subsequente.

\section{O ÍNDICE COMPETITIVIDADE TURÍSTICA ADOTADO PELO MINISTÉRIO DO TURISMO}

A metodologia do Índice de Competitividade Turística adotada pelo Ministério do Turismo surgiu em 2008, quando foi aplicado pela primeira vez nos 65 destinos indutores sob coordenação e execução da Fundação Getúlio Vargas (Barbosa, 2008).

Nesse modelo, considera-se como conceito de competitividade, nas palavras de Barbosa (2008), "a capacidade crescente de gerar negócios nas atividades econômicas relacionadas com o setor de turismo, de forma sustentável, proporcionando ao turista uma experiência positiva" (p. 32).

De acordo com Barbosa e Oliveira (2015), o modelo do Índice de Competitividade Turística propõe a adaptação de estudos de competitividade de autores renomados para adaptar-se melhor à realidade de países em desenvolvimento.

Para operacionalização do conceito de competitividade, foram definidas cinco macro dimensões - Infraestrutura, Turismo, Políticas Públicas, Economia e Sustentabilidade, estruturadas em 13 dimensões, que foram desdobradas em variáveis e estas em perguntas e indicadores. Segundo Barbosa (2008), foram considerados aspectos que "mais qualificam um destino como competitivo no turismo em maior ou menor grau" (p. 32). Para Barbosa e Oliveira (2015), a análise e a composição das dimensões do modelo basearam-se em extensa 
revisão bibliográfica e foram detalhadas por especialistas brasileiros de diferentes áreas.

Figura 1: Dimensões e Variáveis que compõem o Índice de Competitividade Turística.

\begin{tabular}{|c|c|c|c|c|c|c|c|}
\hline \multirow{3}{*}{$\begin{array}{l}\text { DIMENSAO } \\
\begin{array}{l}\text { INFRAESTRUTURA } \\
\text { GERAL }\end{array} \\
\text { ACESSO }\end{array}$} & \multicolumn{7}{|c|}{ VARLÁVEIS } \\
\hline & $\begin{array}{l}\text { Capacidade de } \\
\text { atendimento médico } \\
\text { para o turista no destino }\end{array}$ & $\begin{array}{l}\text { Fomecimento } \\
\text { de energia }\end{array}$ & $\begin{array}{l}\text { Serviço de proteçăo } \\
\text { ao turista }\end{array}$ & $\begin{array}{l}\text { Estrutura urbana } \\
\text { nas treas turisticas }\end{array}$ & & & \\
\hline & $\begin{array}{l}\text { Acesso } \\
\text { aereo }\end{array}$ & $\begin{array}{l}\text { Acesso } \\
\text { rodoviantio }\end{array}$ & Acesso aquarviário & $\begin{array}{l}\text { Acesso } \\
\text { ferroviario }\end{array}$ & $\begin{array}{l}\text { Sistema de } \\
\text { transporte } \\
\text { no destino }\end{array}$ & $\begin{array}{l}\text { Proximidade de } \\
\text { grandes centros } \\
\text { emissivos de } \\
\text { uristas }\end{array}$ & \\
\hline \multirow{2}{*}{$\begin{array}{l}\text { SERVICOS E } \\
\text { EQUIPAMENTOS } \\
\text { TURISTICOS } \\
\text { ATRATIVOS } \\
\text { TURISTICOS }\end{array}$} & $\begin{array}{l}\text { Sinalização } \\
\text { turistica }\end{array}$ & $\begin{array}{l}\text { Centro de } \\
\text { atendimento } \\
\text { ao turista }\end{array}$ & $\begin{array}{l}\text { Espaco para } \\
\text { eventos }\end{array}$ & $\begin{array}{l}\text { Capacidade dos } \\
\text { meics de } \\
\text { hospedagem }\end{array}$ & $\begin{array}{l}\text { Capacidade do } \\
\text { turismo receptivo }\end{array}$ & $\begin{array}{l}\text { Estrutura de } \\
\text { qualificação } \\
\text { para o turismo }\end{array}$ & $\begin{array}{l}\text { Capacidade } \\
\text { dos } \\
\text { restaurantes }\end{array}$ \\
\hline & $\begin{array}{l}\text { Atrativos } \\
\text { natura's }\end{array}$ & $\begin{array}{l}\text { Atrativos } \\
\text { cuturais }\end{array}$ & $\begin{array}{l}\text { Evertos } \\
\text { programados }\end{array}$ & $\begin{array}{l}\text { Realizacões } \\
\text { tecricas, cientlificas } \\
\text { ou artisticas }\end{array}$ & $\begin{array}{l}\text { Diversidade de atrativos, } \\
\text { opsces e equipamentos } \\
\text { de lazer }\end{array}$ & & \\
\hline $\begin{array}{l}\text { MARKETING E } \\
\text { PROMOCCÁAO } \\
\text { DO DESTINO }\end{array}$ & $\begin{array}{l}\text { Plano de } \\
\text { marketing }\end{array}$ & $\begin{array}{l}\text { Participaçăo em } \\
\text { feiras e eventos }\end{array}$ & $\begin{array}{l}\text { Promoçãః } \\
\text { do desino }\end{array}$ & $\begin{array}{l}\text { Estratégias de } \\
\text { promoção digital }\end{array}$ & & & \\
\hline $\begin{array}{l}\text { POLITICAS } \\
\text { PÚBLICAS }\end{array}$ & $\begin{array}{l}\text { Estrutura } \\
\text { municipal para } \\
\text { apoio ao turismo }\end{array}$ & $\begin{array}{l}\text { Grau de } \\
\text { ocoperaça com } \\
\text { o governo estadual }\end{array}$ & $\begin{array}{l}\text { Grau de } \\
\text { coperaçio com } \\
\text { o governo federal }\end{array}$ & $\begin{array}{l}\text { Planejamento para } \\
\text { a cidade e para a } \\
\text { atividade turistica }\end{array}$ & $\begin{array}{l}\text { Grau de cooperacăto } \\
\text { público-privada }\end{array}$ & & \\
\hline $\begin{array}{l}\text { COOPERACÁO } \\
\text { REGIONAL }\end{array}$ & Govemança & $\begin{array}{l}\text { Projetos de } \\
\text { cooperaçato } \\
\text { regional }\end{array}$ & $\begin{array}{l}\text { Planejamento } \\
\text { uristico regional }\end{array}$ & Roteirizaçăo & $\begin{array}{l}\text { Promoçaso e apoio } \\
\text { a comercializaça } \\
\text { de forma integrada }\end{array}$ & & \\
\hline MONITORAMENTO & $\begin{array}{l}\text { Pesquisas de } \\
\text { demanda }\end{array}$ & $\begin{array}{l}\text { Pesquisas de } \\
\text { oferta }\end{array}$ & $\begin{array}{l}\text { Sistema de } \\
\text { estatisticas do } \\
\text { urísmo }\end{array}$ & $\begin{array}{l}\text { Mediçăo dos } \\
\text { impactos da } \\
\text { attividade turistica }\end{array}$ & $\begin{array}{l}\text { Setor especifico } \\
\text { de estudos e } \\
\text { pesquisas }\end{array}$ & & \\
\hline $\begin{array}{l}\text { ECONOMIA } \\
\text { LOCAL }\end{array}$ & $\begin{array}{l}\text { Aspectos da } \\
\text { exonomia local }\end{array}$ & $\begin{array}{l}\text { Infraestrutura de } \\
\text { comuricaças }\end{array}$ & $\begin{array}{l}\text { Intraestrutura e } \\
\text { facilidades para } \\
\text { negócios }\end{array}$ & $\begin{array}{l}\text { Empreendimentos } \\
\text { ou eventos } \\
\text { alavancadores }\end{array}$ & & & \\
\hline $\begin{array}{l}\text { CAPACIDADE } \\
\text { EMPRESARIAL }\end{array}$ & $\begin{array}{l}\text { Capacidade de } \\
\text { qualifcacilo e } \\
\text { aproveitamento } \\
\text { do pessoal local }\end{array}$ & $\begin{array}{l}\text { Presença de } \\
\text { grupos nacionais e } \\
\text { internacionais do } \\
\text { selor do turismo }\end{array}$ & $\begin{array}{l}\text { Concorrência } \\
\text { e barreiras } \\
\text { de entrada }\end{array}$ & $\begin{array}{l}\text { Geraçäo de } \\
\text { negocilose } \mathrm{e} \\
\text { empreendedorismo }\end{array}$ & & & \\
\hline $\begin{array}{l}\text { ASPECTOS } \\
\text { SOCLAIS }\end{array}$ & $\begin{array}{l}\text { Acesso a } \\
\text { educaçAo }\end{array}$ & $\begin{array}{l}\text { Empregos } \\
\text { gerados pelo } \\
\text { turismo }\end{array}$ & $\begin{array}{l}\text { Uso de atrativos } \\
\text { e equipamentos } \\
\text { uristicos pela } \\
\text { Dopulaço }\end{array}$ & $\begin{array}{l}\text { Cidadania, } \\
\text { sensibilização e } \\
\text { participaça na } \\
\text { atividade turistica }\end{array}$ & $\begin{array}{l}\text { Politica de } \\
\text { enfrentamento e } \\
\text { prevençaso a exploraçà } \\
\text { de criancas e adolescentes }\end{array}$ & & \\
\hline $\begin{array}{l}\text { ASPECTOS } \\
\text { AMBIENTAIS }\end{array}$ & $\begin{array}{l}\text { Estrutura e } \\
\text { legisiaciso municipal } \\
\text { de meio ambiente }\end{array}$ & $\begin{array}{l}\text { Atividades em curso } \\
\text { potencialmente } \\
\text { poluidoras }\end{array}$ & $\begin{array}{l}\text { Rede pública } \\
\text { de distribuiç̧ăo } \\
\text { de Água }\end{array}$ & $\begin{array}{l}\text { Rede pública de } \\
\text { coleta e tratamento } \\
\text { de esgoto }\end{array}$ & $\begin{array}{l}\text { Coleta e destinaçăo } \\
\text { pública de residuos }\end{array}$ & $\begin{array}{l}\text { Património natural } \\
\text { e unidades de } \\
\text { conservaç̧o no } \\
\text { território municipal }\end{array}$ & \\
\hline $\begin{array}{l}\text { ASPECTOS } \\
\text { CULTURAIS }\end{array}$ & $\begin{array}{l}\text { Produção } \\
\text { cultural associada } \\
\text { ao turismo }\end{array}$ & $\begin{array}{l}\text { Património } \\
\text { historico cultural }\end{array}$ & $\begin{array}{l}\text { Estrutura } \\
\text { municipal para } \\
\text { apoio à cultura }\end{array}$ & & & & \\
\hline
\end{tabular}

Segundo Barbosa e Oliveira (2015), a análise e a composição das dimensões do modelo proposto basearam-se, primeiramente, numa extensa revisão bibliográfica e, posteriormente, foram detalhadas por especialistas brasileiros de diferentes áreas.

Percebe-se, portanto, que o modelo privilegiou uma análise dos atributos internos, ou recursos do destino (que são importantes para a competitividade turística), baseada na eficiência, ou ex-ante, conforme abordado na seção 2 (Barbosa, 2015). De acordo com Barbosa (2014), "[...] para que os destinos explorem todo o potencial competitivo, é fundamental que se conheçam e se identifiquem os recursos disponíveis, favoráveis ou desfavoráveis, bem como a relação com o ambiente externo" (p. 30). Oliveira (2013) pondera que o conceito apresenta um forte viés econômico, inclusive em relação à sustentabilidade. Ressalta ainda que, apesar de citar a busca pela "experiência positiva" do turista, não apresenta nenhum indicador para captar a percepção do turista, como se aborda a seguir.

Para cada uma das dimensões, variáveis e perguntas do modelo foram atribuídos pesos, levando em consideração as respectivas contribuições 
para o Índice Geral de Competitividade Turística, conforme destacado por Barbosa (2014):

Para que fossem obtidos os índices de competitividade de cada destino, realizaram-se somas ponderadas dos índices obtidos em cada uma das 13 dimensões avaliadas. Assim, os pontos obtidos em cada pergunta foram somados e multiplicados pelo peso da variável correspondente. O somatório desses cálculos corresponde aos índices de cada dimensão (p. 33).

Inicialmente, os critérios de pontuação foram definidos com o apoio de especialistas em cada uma das dimensões e, posteriormente, validado em fórum com a participação de técnicos do Ministério do Turismo, Secretarias Estaduais de Turismo, Sebrae e de representantes de órgãos de classe do turismo e acadêmicos. Os pesos das variáveis e as perguntas foram definidos por um grupo técnico da FGV. O Índice Geral é resultado da soma ponderada das perguntas, variáveis e dimensões (Barbosa, 2008).

A coleta envolve o levantamento de dados secundários disponíveis em fontes oficiais, porém a maior parte das informações é coletada nos destinos, em trabalho de campo. Para fins de comparabilidade entre os destinos, algumas informações são relativizadas, ou seja, ponderadas em relação a porte, receitas públicas, população, entre outros (Barbosa, 2008).

Os pesquisadores da FGV utilizam um questionário para coleta de dados in loco e permanecem cinco dias em cada destino, realizando diversas entrevistas com representantes do poder público, iniciativa privada, sociedade civil, sistema $S$, instituições de ensino, além de observações em atrativos, equipamentos e estruturas. O questionário privilegia aspectos objetivos na avaliação das perguntas e das variáveis, mas quando isso não é possível, os pesquisadores são orientados a realizar triangulações de respostas (fazer a mesma pergunta para vários entrevistados), além de equalizações entre a equipe, para uniformizar ao máximo o entendimento e evitar a subjetividade (Barbosa, 2015). questionário contém, aproximadamente, 600 perguntas categorizadas entre dados secundários, entrevistas ou observação (Barbosa e Oliveira, 2015).

Para análise dos dados, foi elaborado um sistema alimentado com o peso relativo de cada dimensão, variável e pergunta de forma parametrizada 
(Barbosa, 2008). Em razão de a competitividade ser dinâmica, a metodologia, aplicada desde 2008 nos 65 destinos indutores - com exceção de 2012 passou por algumas adaptações, porém manteve sua base, sendo possível a comparabilidade ao longo dos anos (Barbosa, 2014).

Além de um documento contendo os resultados consolidados - denominado Relatório Brasil -, são elaborados relatórios individuais por destino a cada ano, destacando os fatores que influenciaram positivamente e negativamente os resultados de cada dimensão. Nos relatórios, são apresentados gráficos com os resultados de cada município (referente ao Índice Geral e ao resultado de cada dimensão), bem como sua comparação com os anos anteriores e com a média dos 65 destinos pesquisados, considerando capitais e não capitais.

Segundo Barbosa (2015), os Índices de Competitividade foram agrupados em cinco níveis, para fins de análise, sendo: 1) nível 1 - entre 0 e 20 pontos; 2) nível 2 - entre 21 e 40 pontos; 3) nível 3 - entre 41 e 60 pontos; 4) nível 4 - entre 61 e 80 pontos, e 5) nível 5 - entre 81 e 100 pontos.

Nota-se que, desde 2014, o Ministério do Turismo não adota a nomenclatura "65 destinos indutores do desenvolvimento turístico regional" no Relatório Brasil, mantendo apenas "Índice de Competitividade do Turismo Nacional". Percebeuse, desde aquele ano, uma mudança de estratégia em relação aos denominados 65 destinos indutores: estes passaram a ser entendidos como uma amostra da competitividade turística nacional, "representativos da diversidade brasileira" (Barbosa, 2014, p. 24).

Tal percepção é reforçada no Plano Nacional de Turismo 2013-2016, que estabelece, entre seus objetivos, a melhoria e o aumento da competitividade do turismo brasileiro e cita que a amostra, antes limitada à aplicação em 65 destinos (sem fazer referência à palavra "indutores"), poderia ser expandida (Brasil, 2013). Destaca-se, portanto, uma descontinuidade no que diz respeito à política inicialmente estabelecida de estruturação dos 65 destinos indutores, o que pode ter sido influenciado, em parte, pelas sucessivas trocas de gestão (bem como de parte da equipe) do Ministério: de 2008 a 2015, passaram pelo MTur seis diferentes ministros. Apesar disso, a aplicação do Índice se manteve nos mesmos destinos em 2014 e 2015. 
A pesquisa é de natureza qualitativa, descritiva e exploratória. A metodologia qualitativa tem o intuito de aproximar e de criar certo grau de intimidade e confiança entre sujeito e objeto (Dencker, 2007; Severino, 2013). "O pesquisador tem empatia com os motivos, as intenções, os projetos dos atores, a partir dos quais as ações, as estruturas e as relações tornam-se significativas [...]" (Minayo, 1993, p. 245). Veal (2011) destaca que a pesquisa descritiva tem a finalidade de "descrever, o máximo possível, o objeto de estudo" sem focar na explicação em si (p. 71).

O procedimento de campo consistiu em análise documental e em aplicação de entrevistas com questões abertas, visando proporcionar liberdade para o aprofundamento das respostas (Minayo, 1993; May, 2004). Aplicou-se a análise de conteúdo, que, para Bardin (2011), deve seguir os procedimentos de pré-análise, codificação, categorização e inferência, com base nas respostas. Trata-se de técnica para descrever e interpretar o conteúdo de toda classe de documentos e textos. Orienta-se por critérios como: contexto, objeto ou corpus, questões formuladas, objetivos da pesquisa, subjetividade e isenção científica do pesquisador (Barros e Lehfeld, 1991; Moraes, 1994).

As categorias que constituíram o procedimento analítico foram: contribuições do Índice de Competitividade para o destino; visão quanto a aspectos positivos do Índice de Competitividade no que diz respeito a: metodologia, periodicidade de aplicação, relatórios com os resultados finais, aplicabilidade (utilização pelas organizações do destino); limitações do Índice com relação a: metodologia, periodicidade de aplicação, relatórios com os resultados finais, aplicabilidade (utilização pelas organizações do destino); e desafios e perspectivas no que diz respeito à utilização e à continuidade do Índice de Competitividade.

A amostra selecionada para as entrevistas teve como critério de seleção possuir vínculo institucional ou contratual com as instituições envolvidas no projeto (MTur, FGV e Sebrae Nacional) e acompanhar tecnicamente a aplicação do índice - selecionados a partir das fichas técnicas dos relatórios finais do estudo.

Os entrevistados foram 14 técnicos do Ministério do Turismo ligados à coordenação geral de estruturação de destinos e ao departamento de estatística; gestores, coordenadores e técnicos da Fundação Getúlio Vargas, 
além dos pesquisadores de campo, que participaram dos dois últimos anos do projeto, bem como técnicos e analistas do Sebrae Nacional, ligados à Unidade de Atendimento Setorial - Serviços, que acompanharam o projeto.

As entrevistas foram realizadas no período de 11 de abril a 15 de maio de 2016, por meio da ferramenta de questionários web Survey Monkey. O procedimento de coleta envolveu o envio do questionário on-line por e-mail, seguido de contatos telefônicos de modo a explicar a pesquisa e sensibilizar para participação.

As questões abordadas envolveram a opinião sobre a contribuição dos resultados do índice para os destinos; os aspectos positivos percebidos; as limitações metodológicas e os desafios e as perspectivas para utilização e continuidade da aferição da competitividade turística pelo MTur. As respostas foram abertas, sendo permitida a opinião livre dos entrevistados acerca das questões.

As respostas obtidas foram então categorizadas por assunto, considerando os tópicos aspectos positivos, limitações metodológicas, periodicidade de aplicação, relatórios finais, aplicabilidade, desafios e perspectivas.

Além das entrevistas supracitadas, utilizou-se também a técnica de observação participante, quando o pesquisador "torna-se parte do processo social que está sendo estudado" (Veal, 2011, p. 275). Isso se deve ao fato de a autora do presente artigo ter sido pesquisadora da Fundação Getúlio Vargas, integrando a equipe de campo do Índice de Competitividade Turística de 2013 a 2015.

\section{RESULTADOS E DISCUSSÕES}

Conforme abordado anteriormente, a competitividade é um conceito de difícil definição e mensuração (Ritchie e Crouch, 2003; Cinicioglu et al, 2013; Oliveira, 2013; Ruize Gândara, 2014). A metodologia do índice de competitividade turística desenvolvida pela FGV em parceria com o MTur e o Sebrae Nacional destinos indutores surgiu como uma ferramenta de mensuração e monitoramento, objetivando fornecer um diagnóstico ao destino que subsidie a tomada de decisão no que se refere ao desenvolvimento do turismo (Barbosa, 2008). 
Nesse sentido, a primeira questão abordada junto aos entrevistados foi se os resultados do Índice de Competitividade Turística efetivamente contribuíam com o destino (na visão pessoal de cada um) e, caso positivo, em quais aspectos. A grande maioria, com exceção de um entrevistado, respondeu que sim. A maior recorrência de respostas sobre essa contribuição positiva foi relacionada ao subsídio oferecido aos destinos para o planejamento de ações, definição de políticas públicas adequadas e tomada de decisão sobre o desenvolvimento e a estruturação do turismo, conforme trechos das respostas a seguir:

[...] Quanto maisinterpretadassão as variáveis abordadas (planejamento, cooperação, políticas públicas, parcerias público-privadas, etc.) mais capaz será o destino de explorar contribuições, pois diversas ações podem ser aplicadas para proporcionar aos destinos avanço no desenvolvimento da atividade. (Entrevistado 1 - FGV)

O índice aborda um panorama geral do destino e, na medida em que identifica forças e fraquezas, pode ser utilizado para nortear planejamento e ações (Entrevistado 6 - MTur)

O índice fornece informações e dados que possibilitam a adoção de políticas e a implementação de ações para que o destino avance [...] (Entrevistado 11 - Sebrae Nacional).

Percebe-se que o índice é valorizado por diagnosticar a competitividade dos atributos internos do destino, a partir do entendimento de que, conhecendo e identificando os recursos que impactam no turismo - de maneira positiva ou negativa -, é possível definir estratégias mais subsidiadas ao seu desenvolvimento (Oliveira, 2013; Barbosa, 2015). Mais importante do dado ligado à competitividade é, portanto, sua interpretação e transformação em ação efetiva.

Além destes, foram citadas a sua relevância para o monitoramento da competitividade e a avaliação de avanços e de gargalos para o desenvolvimento turístico.

Utilizando a ferramenta de nuvem de palavras a partir das respostas obtidas nessa pergunta (Figura 2), percebe-se o destaque de alguns desses termos, tais como planejamento, desenvolvimento, informações, resultados e políticas. 
Figura 2: Palavras mais utilizadas pelos entrevistados quando questionados sobre a contribuição positiva dos resultados do índice

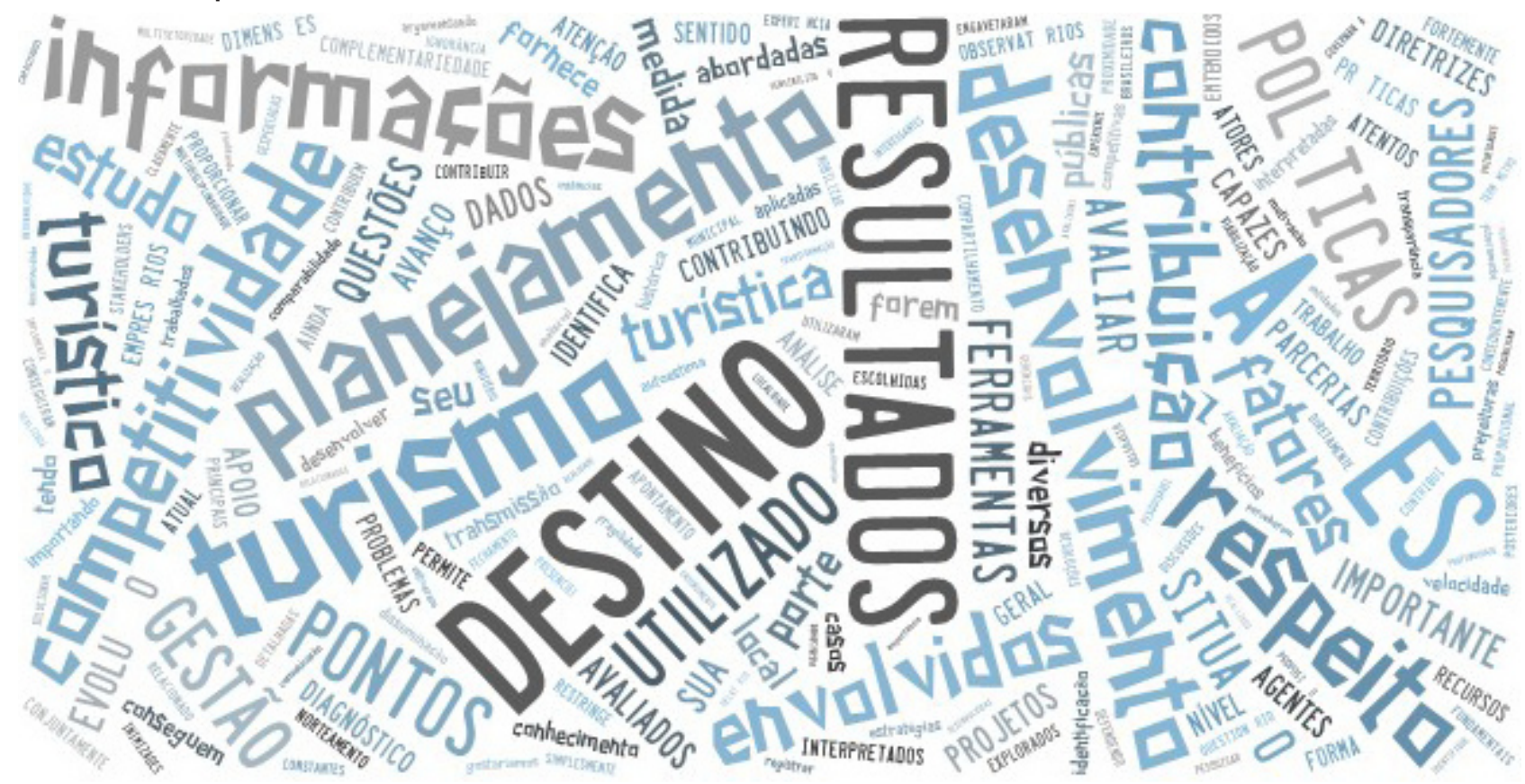

Fonte: Elaboração própria (2016)

Um dos respondentes destacou que acredita que o momento da entrevista durante o trabalho de campo é também importante pois, à medida que são realizadas as perguntas, os entrevistados mais atentos percebem que podem ser realizadas algumas ações, no âmbito de sua área de atuação, que podem contribuir para a melhoria da competitividade turística do destino. A troca de experiências entre o pesquisador e o entrevistado também foi citada: 0 primeiro, que tem contatos com experiências de outros destinos, contribui com o relato de algumas práticas exitosas, que podem ser replicadas ou servirem de inspiração para soluções:

[...] transmissão de conhecimento prático/teórico do pesquisador para os entrevistados: o pesquisador já esteve em diversos destinos e absorveu boas práticas que podem solucionar e amenizar problemas dos destinos que irá pesquisar futuramente. (Entrevistado 8 - FGV)

Destacou ainda que o trabalho de campo mobiliza diversos atores do turismo, algumas vezes, reunindo pessoas que pouco se conhecem, ou se encontram em uma mesma entrevista, o que contribui para discussão construtiva acerca do turismo no destino e aproximação dos atores:

A viabilização da pesquisa mobiliza diversos atores da área do turismo no destino, o que claramente gera debates e aproxima os envolvidos. 
Não foram poucas as vezes em que presenciei fechamento de parcerias, resoluções de problemas e reduções de inimizades durante entrevistas (Entrevistado 8 - FGV)

A carência de dados relativos ao turismo na maioria dos municípios também foi mencionada por vários entrevistados, que consideram o Índice uma ferramenta importante:

Carecemos de dados para apoio à tomada de decisões gerenciais de uma forma geral no Turismo. O índice preenche algumas lacunas interessantes neste sentido, já que fornece tanto ao Ministério, quanto aos destinos que conseguem usar, um termômetro da atividade no país em 13 dimensões. (Entrevistado 9 - Pesquisador FGV)

Tendo em vista a realidade da maioria dos destinos, que carecem que informações relacionadas ao monitoramento e à análise da situação atual [...], o Índice de Competitividade tem papel fundamental em avaliar de forma objetiva a situação atual do destino [...] (Entrevistado 12 - Sebrae Nacional)

Além destes, destacou-se que o Índice oferece um diagnóstico objetivo e imparcial da competitividade turística, do ponto de vista dos recursos internos de cada destino. A única crítica foi que os relatórios permitem apenas uma análise superficial da realidade e, para servir efetivamente como orientador de políticas públicas, o Índice de Competitividade deveria reavaliar seus objetivos e propósitos.

Com relação à opinião sobre os aspectos positivos, além das limitações do Índice de Competitividade a partir da experiência dos entrevistados, separouse essa avaliação em 4 itens principais: a. Metodologia; b. Periodicidade de aplicação, c. Relatórios com os resultados finais (informações descritas, formato, nível de aprofundamento) e d. Aplicabilidade (uso pelo destino e instituições interessadas).

As respostas obtidas com relação ao tópico a. Metodologia foram agrupadas em categorias, apresentadas no Quadro 02. Não foram citadas apenas as respostas que remeteram a juízo de valor, não explicadas de maneira mais detalhada, tais como "solidez", "metodologia consistente e inovadora para o setor", "boa metodologia", "não é suficientemente robusto", entre outras. 
Quadro 02: Aspectos Positivos e Limitações do Índice de Competitividade Turística

\begin{tabular}{|c|c|c|}
\hline Categoria & Aspectos Positivos & Limitações \\
\hline $\begin{array}{c}\text { Uniformidade } \\
\text { metodológica }\end{array}$ & $\begin{array}{c}\text { Método único para todos os destinos, } \\
\text { permitindo comparabilidades entre eles; } \\
\text { Possibilidade de visualizar a competitividade } \\
\text { turística em âmbito nacional }\end{array}$ & $\begin{array}{c}\text { Por ser uma metodologia única, não } \\
\text { são feitas ponderações de acordo com } \\
\text { a realidade do destino }\end{array}$ \\
\hline Subjetividade & Imparcialidade do pesquisador & $\begin{array}{c}\text { É frequente que mudanças de gestão } \\
\text { nos municípios provoquem respostas } \\
\text { diferentes para uma mesma questão, } \\
\text { ano a ano; } \\
\text { Muitas análises são subjetivas e ficam a } \\
\text { critério do pesquisador. }\end{array}$ \\
\hline
\end{tabular}

Fonte: Elaboração própria (2016)

Quando questionados acerca dos aspectos positivos relacionadas ao item b. Periodicidade de aplicação, os entrevistados responderam que a realização anual dos estudos é importante para manter os dados atualizados, compondo uma séria histórica relevante, o que permite o monitoramento da competitividade turística dos destinos. As limitações, porém, da aplicação anual, foram destacados de maneira mais incisiva: os respondentes afirmaram que há pouca variação de um ano para outro, uma vez que grande parte das ações executadas somente são percebidas em médio ou longo prazo, fazendo com que a evolução seja "lenta e pouco estimulante". Nesse contexto, alguns respondentes sugeriram que a aplicação fosse a cada dois anos ou, até mesmo, que houvesse duas versões: uma mais sintética, realizada anualmente; e uma mais completa, com periodicidade bienal.

Entre as características positivas do item c. Relatórios com os resultados finais, citaram-se a linguagem direta e objetiva e a utilização de gráficos, que facilitam a visualização e a compreensão, também da série histórica. A elaboração de relatórios individualizados por destino foi avaliada como positiva. Destacou-se, porém, que os relatórios são muito padronizados e poderiam ser mais dinâmicos e interativos, com linguagem mais personalizada e aprofundada para cada destino. Citou-se ainda que os relatórios são repetitivos de um ano para outro. Um dos entrevistados justificou que o tempo limitado para realização do estudo é um dos aspectos que influenciam a carência de maior aprofundamento dos relatórios: 
Os relatórios finais, também devido à característica do estudo, não se aprofundam em cada tópico. Isso acontece, em primeiro lugar, pela necessidade de imparcialidade na exposição dos resultados e, por outro pelo tempo disponível após a pesquisa para elaborar 65 relatórios para serem entregues (Entrevistado 13 - FGV).

O último item abordado nessa relação, aspectos positivos versus limitações, foi o d. Aplicabilidade. Nesse item, buscou-se investigar a opinião dos entrevistados sobre a utilização dos dados oriundos do estudo pelo destino e pelas instituições interessadas. Como aspectos positivos, foram citados o subsídio para o planejamento e políticas públicas, assim como para outras pesquisas, quando os atores do destino se apropriam dos resultados. Apesar disso, vários respondentes consideram que o estudo é pouco aplicado: "O uso se dá de forma muito abrangente e superficial, não sendo um fator decisivo para auxiliar na construção de novas políticas públicas para o setor" (Entrevistado 11 - MTur). Ou ainda:

Falta compreendê-lo como uma ferramenta a ser complementada por outras ações - de planejamento, de marketing, de capacitação para a cooperação entre público e privado. Por ser pouco compreendida, seu uso na grande maioria dos destinos se esgota em seu propósito inicial - geração de indicador (Entrevistado 2 - FGV).

Além dos aspectos citados anteriormente, foi disponibilizado um campo aberto como "outros" para apontamentos de distintos itens positivos, ou limitações acerca do Índice, não contemplados nos itens anteriores. Nesse campo, foram apontadas como limitações do estudo as falhas de comunicação entre as instituições envolvidas na aplicação do índice (FGV, MTur e Sebrae Nacional) e a limitada amostra de 65 destinos.

Por fim, questionou-se sobre os desafios e as perspectivas da utilização e continuidade do Índice, na visão pessoal de cada entrevistado. Foram mencionadas desde questões operacionais e metodológicas do Índice, tais como "tornar o campo mais enxuto", "revisão da metodologia", "refazer análise sobre periodicidade", até aquelas ligadas a indefinições por parte do MTur, no que diz respeito à política, que motivou a criação dos 65 destinos indutores e os recursos desprendidos para aplicação do estudo: 
Sem a definição sobre os 65 destinos pesquisados (são ou não prioritários?) a aplicação do Índice não se justifica apenas por se tratar de uma série histórica. Além disso, é preciso que os destinos que recebem o estudo tenham maior responsabilidade com os resultados e algo seja feito na prática. É muito dinheiro envolvido para ser apenas mais um estudo (Entrevistado 3 - Sebrae Nacional).

A necessidade de aguardar uma estabilização do cenário político do Governo Federal, que impacta diretamente nas ações do MTur, também foi mencionada. O desafio de tornar a utilização efetiva dos resultados do índice foi também amplamente destacado:

\begin{abstract}
Quanto à utilização, creio que o principal desafio seja fazer com que atores locais do turismo nos destinos entendam, definitivamente, que o Índice não visa fazer uma auditoria nos destinos, mas 'muni-los' de informações que guiem suas políticas e ações. Além disso, os atores locais precisam ser incentivados e ensinados a utilizar o estudo, seja por meio de oficinas, seja por meio de estratégias de comunicação mais efetivas. Quanto à continuidade, vejo que depende do interesse (técnico e político) dos clientes (MTur e Sebrae), que pode ou não estar relacionado à comprovação da importância e da utilização do estudo, ainda que esta seja um bom caminho para incentivar novas contratações (Entrevistado 8 - Pesquisador FGV).
\end{abstract}

A seguir, serão apresentadas as principais conclusões da pesquisa realizada, com base na fundamentação teórica.

\title{
CONSIDERAÇÕES FINAIS
}

O objetivo deste artigo foi analisar os desafios, os aspectos limitantes e as perspectivas do modelo do Índice de Competitividade Turística no contexto da política nacional de turismo brasileira, a partir da opinião de técnicos do MTur, da FGV e do Sebrae Nacional. Nesse sentido, ressalta-se que os dados apresentados oferecem apenas a visão pessoal dos entrevistados, mas contribuem para conclusões acerca da eficácia do estudo para melhoria da competitividade dos destinos.

O conjunto de resultados mostram que o Índice de Competitividade Turística adotado pelo Ministério do Turismo é visto como uma ferramenta que pode contribuir positivamente para o destino, seja como subsídio para planejamento 
e formulação de políticas públicas, ou apenas para monitoramento e avaliação de avanços e retrocessos, além de ser uma fonte de dados acerca de aspectos importantes ao turismo. O fato de a metodologia do Índice envolver, além da análise de dados secundários, a pesquisa de campo propicia um contato mais profundo com o território e com atores representativos do turismo local. A existência de um método unificado para todos os destinos e de uma série histórica considerável é um fator destacável em um país cujos dados estatísticos acerca do turismo são escassos, ainda mais quando considerada a unidade local, ou seja, o município.

Apesar disso, foram apontadas algumas limitações importantes que devem ser consideradas e servem como reflexões para revisão da estratégia ligada ao Índice, assim como para aprimoramento da metodologia. No que se refere aos aspectos metodológicos, o excesso de uniformidade na forma de coleta e análise dos resultados, não considera as diferentes realidades dos destinos. Isso se reflete também nos relatórios que são entregues aos destinos: a padronização e o formato foram considerados pouco dinâmicos e limitados, em termos de aprofundamento, além de repetitivos, considerando a aplicação anual. Este, inclusive, foi outro aspecto apontado como frágil pois, apesar de ser interessante contar com um monitoramento anual, a periodicidade foi apontada como excessiva, havendo pouca variação de resultados de um ano para outro, o que pode desestimular os gestores públicos e demais atores do turismo local, pois grande parte das ações são percebidas em médio e longo prazo.

Ainda com relação à metodologia, destaca-se que o Índice não considera a opinião da demanda, conforme já destacado por Oliveira (2012) e, sendo o turista um elo fundamental da cadeia do turismo, seria importante pesquisar a percepção dele acerca da competitividade.

No que se refere aos desafios e às perspectivas, constatou-se a visão unânime entre os respondentes de que os resultados do Índice de Competitividade ainda são subutilizados pelos destinos e demais instituições interessadas, tal como o próprio Ministério do Turismo. Nesse aspecto, é necessário lembrar que a amostra dos anteriormente chamados de 65 destinos indutores foi, a princípio, definida como parte de uma estratégia da política nacional de 
turismo capitaneada pelo MTur, integrante de um programa, com o objetivo de concentrar esforços para estruturação de tais destinos.

Percebe-se, claramente, a falta de manutenção da estratégia inicial: tal política foi descontinuada, os destinos deixaram de ser denominados de indutores, e o Índice de Competitividade Turística passou a ser uma ferramenta apenas de monitoramento ou de diagnóstico para os destinos. De certa forma, pode-se considerar que os resultados do Índice foram pouco absorvidos e utilizados na definição de prioridades de ações do próprio MTur. Conforme destacado, as sucessivas mudanças de gestão e de técnicos do MTur podem ter contribuído para tal descontinuidade.

Por fim, para conclusões mais consistentes acerca da efetividade e da utilização dos dados oriundos do Índice de Competitividade Turística, considera-se importante aprofundar a investigação aqui realizada, acrescentando indagações e ampliando a amostra dos entrevistados para atores do turismo nos destinos, tais como empresários, gestores públicos municipais, líderes de associações, representantes de Conselhos e de escritórios estaduais e regionais e do Sebrae.

REFERÊNCIAS

Alves, S., Ferreira N. N. Medida da competitividade do destino Brasil: uma aplicação do Índice de Competitividade Turística do WEF 2008. Revista Observatório de Inovação do Turismo, Vol IV, N. ${ }^{\circ} 2$.

Anjos, F. (2004). Processo de planejamento e gestão de territórios turísticos, uma proposta sistêmica. Tese de Doutorado. Universidade Federal de Santa Catarina. Programa de PósGraduação em Engenharia da Produção.

Anjos, F.; Anjos, S.; Oliveira, J. (2013). Abordagem Sistêmica no processo de planejamento e gestão de territórios urbanos turísticos. Revista Rosa dos Ventos, 5(3), pp. 390 - 407.

Araújo, C. M., César, P. A. B (2012). Dimensão política institucional do turismo no Brasil. In: Turismo: planejamento estratégico e capacidade de gestão. Desenvolvimento regional, rede de produção e clusters. Barueri/SP: Manole.

Araújo, C. M., Taschner, G. (2012). Turismo e políticas públicas no Brasil. In: Turismo: planejamento estratégico e capacidade de gestão. Desenvolvimento regional, rede de produção e clusters. Barueri/SP: Manole. 
Barbosa, L. G. (Org) (2008). Estudo de Competitividade dos 65 Destinos Indutores do Desenvolvimento Turístico Regional - Relatório Brasil. 2a edição revisada. Brasília/DF: Ministério do Turismo.

(2009). Estudo de Competitividade dos 65 Destinos Indutores do Desenvolvimento Turístico Regional - Relatório Brasil 2009. Brasília/DF.

(2010). Índice de Competitividade do Turismo Nacional: 65 Destinos Indutores do Desenvolvimento Turístico Regional - Relatório Brasil 2010. Brasília/DF.

(2011). Índice de Competitividade do Turismo Nacional: 65 Destinos Indutores do Desenvolvimento Turístico Regional - Relatório Brasil 2013. Brasília/DF.

(2013). Índice de Competitividade do Turismo Nacional: Destinos Indutores do Desenvolvimento Turístico Regional - Relatório Brasil 2013. Brasília/DF.

(2013). Plano Nacional de Turismo 2013/2016. Recuperado em 06 de abril de 2016, de http://www.turismo.gov.br/2015-03-09-13-54-27.html

(2014). Índice de Competitividade do Turismo Nacional - Relatório Brasil 2014. Brasília/DF.

(2015). Índice de Competitividade do Turismo Nacional - Relatório Brasil 2015. Brasília/DF.

(2016). Relatórios do Índice de Competitividade Turística. Recuperado em 06 de abril de 2016, de http://www.turismo.gov.br/publicacoes/item/29-indice-de-competitividadedo-turismo-nacional.html

Barbosa, L. G. (2012). The competitiveness of brazilian tourist destinations. Thesis (PhD), Nottingham University Business School, Nottingham. University of Nottingham.

Barbosa, L. G., Oliveira, C. T. F. (2015). The competitiveness of Brasilian tourist destination. In: International Journal of Strategic Change Management (ISCM), Vol 6, No 1.

Bardin, L. (2011). Análise de conteúdo. São Paulo: Edições 70.

Barros, A. J. P.; Leuhfeld, N. A. S. (1991). Projeto de pesquisa: propostas metodológicas. Petrópolis: Vozes.

Botti, L., Peypoch, N., Robinot, E., Solonadrasana, B. (2009). Tourism destination competitiveness: The French regions case. European Journal of Tourism Research, v. 2, n. 1, p. 5-24.

Brasil, Ministério do Turismo (2007). Plano Nacional de Turismo 2007/2010 - Uma Viagem de Inclusão. Recuperado em 06 de abril de 2016, de http://www.turismo.gov.br/ 
Dor: 10.14210/rtva.v18n2.p292-318 sites/default/turismo/o_ministerio/publicacoes/downloads_publicacoes/plano_nacional_ turismo_2007_2010.pdf

Brasil, Ministério do Turismo (2013). Plano Nacional de Turismo 2013/2016 - O turismo fazendo muito mais pelo Brasil. Recuperado em 06 de abril de 2016, de www.turismo.gov. br/images/pdf/plano_nacional_2013.pdf

BUHALIS, D. (2000). Marketing the Competitive Destination of the Future. Tourism Management, v. 21, n. 1, p. 97-116.

Cinicioglu, E. N., et al (2013). The Basic Competitiveness Factors Shaping the Innovation Performance of Countries. In: International IIE (Institute of Industrial Engineers) Conference (IIE 2013): The Global Reach of Industrial Engineering, Istanbul, Turkey. Recuperado em 06 de abril de 2016, de http://research.sabanciuniv.edu/25012/

Crouch, G. I. (2007). Modelling Destination Competitiveness: a survey and analysis of the impact of competitiveness attributes. Australia: CRC for Sustainable Tourism.

Crouch, G. I. Measuring tourism competitiveness: research, theory and the WEF Index (2007b). Autralian and New Zealand Marketing Academy. Conference 2007. Reputation, responsibility \& relevance. University of Otago, Dunedin, New Zealand, 3 a 5 dezembro de 2007. Recuperado em 06 de abril de 2016, de http://www.anzmac.org/conference_ archive/2007/papers/Crouch_1.pdf

Dencker, A. F M. (2007). Métodos e técnicas de pesquisa em turismo. São Paulo: Futura.

Dwyer, L., Kim, C (2003). Destination Competitiveness: determinants and indicators. Current Issues in Tourism, 6, 369-414.

Enright, M. J.; Newton, J. (2004). Tourism destination competitiveness: a quantitative approach. Tourism Management, v. 25, n. 6, p. 777-788.

Gandara, J. M. et al (2012). A qualidade da experiência na visitação de destinos turísticos. In: Turismo: planejamento estratégico e capacidade de gestão. Desenvolvimento regional, rede de produção e clusters. Barueri/SP: Manole.

Gooroochurn, N.; Sugiyarto, G. (2005). Competitiveness indicators in the travel and tourism industry. Tourism Economics, v. 11, n. 1, p. 25-43,.

Haguenauer, L (1989). Competitividade: Conceitos e Medidas. Texto para Discussão, IEI/ UFRJ, n. 211, 1989,mimeo. Recuperado em 06 de abril de 2016, de http://www.ie.ufr.bf/gic/ pdfs/1989-1_Haguenauer.pdf

Knezecic Cvelbar, L., Dwyer, L., Koman, M., Mihalic, T. (2016). Drivers of Destination Competitiveness in Tourism : A Global Investigation. Journal of Travel Research, n. 55, p. 1042-1050 
Lohmann, G.; Panosso Neto, A. (2012). Teoria do turismo: conceitos, modelos e sistemas. 2.ed. Rev. Ampl. São Paulo: Aleph.

May, T. Pesquisa social: questões, métodos e processos. Porto Alegre: Artmed, 2004.

Mazanec, J. A.; Wober, K; Zins, A.H. (2007). Tourism Destination Competitiveness: From Definition to Explanation? Journal of Travel Research, v. 46, n. August, p. 86-95, 2007.

Mazaro, R. e Varzin, G. (2008). Modelos de Competitividad para destinos turísticos en el marco de la sostenibilidad. RAC. Curitiba, pp. $789-809$.

Mazurek, M. (2014). Competitiveness in Tourism - models of tourism competitiveness and their applicability: case study Austria and Switzerland. In: European Journal of Tourism, Hospitality and Recreation, pp. 73-94, Portugal.

Minayo, M. C.; Sanches, O. (1993). Quantitativo-qualitativo: oposição ou complementaridade? Faculdade Saúde Pública, Rio de Janeiro, Vol. 9, n. 3, p. 239-262

Moraes, R. (1994). Análise de conteúdo: limites e possibilidades. In: ENGERS, M. E. A. (Org). Paradigmas e metodologias de pesquisa em educação. Porto Alegre: EDIPUCRS.

Oliveira, C. F. de. (2013). Competitividade de destinos turísticos: fatores de demanda e de desempenho. Tese de Doutorado, Escola Brasileira de Administração Pública e de Empresas, Fundação Getúlio Vargas, Rio de Janeiro/RJ.

Olsen S., et al (2008). A new perspective on the competitiveness of nations. Socio-economic Planning Sciences, 42 (4), p. 221-246. Recuperado em 12 de abril de 2016, de https://research. sabanciuniv.edu/799/1/3011800000398.pdf

OrganizaçãoMundial deTurismo(2015).UNWTO:TourismHighlights-2015Edition.Recuperado em 6 de abril de 2016, de http://www.e-unwto.org/doi/book/10.18111/9789284416899

Porter, M. (1985). Competitive Advantage: Creating and Sustaining Superior Performance. Free Press, New York.

Porter, M. (1990). The Competitive Advantage of Nations. Free Press, New York.

Ritchie, J.R.B., Crouch, G.I. (2003). The Competitive Destination: a sustainable tourism perspective. Washington - USA: CABI Publishing. 
Ruiz, T. C. D., Gândara, J. M. (2014). O Planejamento Urbano e a Competitividade de Destinos Turísticos: uma análise da perspectiva do modelo de Dwyer e Kim. In: Turismo em Análise (Vol 25), pp. 580-607.

Schuch, C. H. (2001). Desempenho da cadeia produtiva da indústria do Turismo. In: Barretto Margarita e REJOWSKI, Mirian (Orgs.). Turismo: interfaces, desafios e incertezas (pp. 35 -46). Caxias do Sul: EDUCS.

Severino, A. J. (2013). Metodologia do trabalho científico. São Paulo: Cortez.

Tomazzoni, E. L. (2007). Turismo e desenvolvimento regional: modelo APL TUR aplicado à Região das Hortênsias (RS, Brasil). Tese de Doutorado. Programa de Pós-Graduação em Comunicação (Relações Públicas, Propaganda e Turismo) da Escola de Comunicações e Artes (ECA). Universidade de São Paulo (USP).

United World Tourism Organization- UNWTO (2015). UNWTO: Tourism Highlights - 2015 Edition. Madri, Espanha.

Veal, A., J. (2011). Metodologia de Pesquisa em Lazer e Turismo. São Paulo: Aleph.

World Economic Forum - WEF (2015). The Global Competitiveness Report 2015-2016. Recuperado em 12 de abril de 2016, de http://www3.weforum.org/docs/gcr/2015-2016/ Global_Competitiveness_Report_2015-2016.pdf

\section{CONTRIBUIÇÃO DOS AUTORES NA CONSTRUÇÃO DO ARTIGO}

SETTE: Pesquisa bibliográfica e documental, elaboração do instrumento de pesquisa primária, aplicação da pesquisa, análise dos dados, redação do artigo.

TOMAZZONI: Pesquisa bibliográfica e documental, orientação acerca da elaboração do instrumento de pesquisa primária, orientação na análise dos dados, redação e revisão do artigo. 